JAMP: Jurnal Adminitrasi dan Manajemen Pendidikan Volume 2 Nomor 3 September 2019, Hal : 90-97

Tersedia Online di http://journal2.um.ac.id/index.php/jamp/ ISSN 2615-8574 (online)

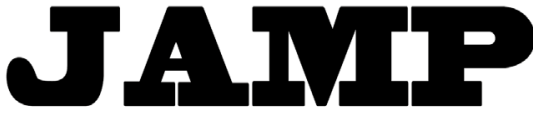

JURNAL ADMINISTRASI DAN MANAJEMEN PENDIDIKAN

\title{
Budaya Sekolah dan Etika Profesi: Pengukuran Pemberdayaan Sumber Daya Manusia Sekolah dengan Pendekatan Soft System Methodology
}

\author{
Desi Eri Kusumaningrum, Raden Bambang Sumarsono, Imam Gunawan
}

\author{
Universitas Negeri Malang, Jalan Semarang 5 Malang 65145 \\ Email: desi.eri.fip@um.ac.id
}

\begin{abstract}
Professional ethics is something that teachers need to uphold in carrying out their profession. The application of professional ethics is rooted in school culture as an educational institution that upholds the values and norms of society. The hypothesis of this study is that there is a significant influence of school culture variables $(\mathrm{X})$ on professional ethics $(\mathrm{Y})$. To answer this hypothesis, then make this research use quantitative research. The instrument used to measure the research variables was a closed questionnaire, so respondents chose alternative answers provided. The respondents of this study consisted of 31 people, consisting of: 1 principal; 20 teachers; and 10 school administrators. The study was conducted at Junior High School An Nur, Bululawang, Malang Regency, East Java, Indonesia. Data analysis uses simple regression. Based on the results of data analysis, it was concluded that there was an influence of school culture $(\mathrm{X})$ on professional ethics $(\mathrm{Y})$, with a regression coefficient of 0.537 . The formed regression equation is $\hat{\mathrm{Y}}=28.923+0.43 \mathrm{X}$.
\end{abstract}

Keywords: school culture, professional ethics, soft systems methodology

\begin{abstract}
Abstrak: Etika profesi merupakan hal yang perlu dijunjung tinggi oleh para guru dalam melaksanakan tugas profesi guru. Penerapan etika profesi berakar pada budaya sekolah sebagai lembaga pendidikan yang menjunjung tinggi nilai dan norma kemasyarakat. Hipotesis penelitian ini adalah ada pengaruh yang signifikan variabel budaya sekolah $(X)$ terhadap etika profesi $(\mathrm{Y})$. Untuk menguji hipotesis tersebut, maka penelitian ini menggunakan rancangan penelitian kuantitatif. Instrumen yang digunakan untuk mengukur variabel penelitian adalah angket tertutup, sehingga responden memilih alternatif jawaban yang telah disediakan. Responden penelitian ini berjumlah 31 orang, terdiri dari: 1 orang kepala sekolah; 20 orang guru; dan 10 orang tenaga administrasi sekolah. Penelitian dilaksanakan di SMP An Nur Bululawang Malang Jawa Timur. Analisis data menggunakan regresi sederhana. Berdasarkan hasil analisis data disimpulkan ada pengaruh budaya sekolah $(\mathrm{X})$ terhadap etika profesi $(\mathrm{Y})$, dengan koefisien regresi 0,537 . Persamaan regresi yang terbentuk adalah $\hat{Y}=28,923+0,43 X$.
\end{abstract}

Kata kunci: budaya sekolah, etika profesi, soft system methodology

Organisasi pendidikan seperti organisasi pada umumnya juga memiliki budaya yang menjadi ciri khas organisasi tersebut. Sekolah sebagai organisasi pendidikan, di dalamnya terdapat budaya sekolah yang tumbuh dan berkembang. Tumbuh dan berkembangnya budaya sekolah ditentukan oleh sikap, pola pikir, dan perilaku orang-orang yang ada di sekolah. Budaya sekolah hidup bersamaan dengan "pola hidup" warga sekolah. Sehingga budaya sekolah memiliki variasi dan keunikan sendiri. Budaya sekolah mengacu pada cara warga sekolah (kepala sekolah, guru, dan anggota staf lainnya) bekerja bersama dan seperangkat keyakinan, nilai, dan asumsi yang mereka percayai. Budaya sekolah meningkatkan kemampuan siswa untuk belajar (Suminah, dkk., 2018; Gunawan, 2017; Hardika, dkk., 2018; Mursidik, dkk., 2013; Suraya, dkk., 2012).

Budaya sekolah adalah salah satu konsep paling kompleks dan penting dalam pendidikan. Schein (2014) menganggap esensi dasar dari budaya organisasi adalah tingkat yang lebih dalam dari asumsi 
dasar dan kepercayaan yang dimiliki oleh anggota organisasi, yang beroperasi secara tidak sadar, dan yang mendefinisikan dalam dasar "menerima begitu saja" pandangan organisasi tentang dirinya dan lingkungannya. Inilah jantung budaya sekolah dan apa yang membuatnya begitu sulit untuk dipahami dan diubah. Sebagian besar kepala sekolah memiliki kesadaran naluriah bahwa budaya organisasi adalah elemen kunci keberhasilan sekolah.

Mereka mungkin mengatakan sekolah mereka memiliki budaya yang baik ketika guru mengekspresikan visi bersama dan siswa berhasil, atau bahwa mereka perlu bekerja pada budaya sekolah ketika beberapa guru mengundurkan diri atau tingkat disiplin siswa meningkat. Tetapi seperti banyak pemimpin organisasi, kepala sekolah mungkin terhalang ketika mereka benar-benar mencoba menggambarkan elemen-elemen yang menciptakan budaya positif. Sulit untuk didefinisikan, dan mengurai komponennya bisa jadi menantang. Di tengah dorongan untuk hasil nyata seperti nilai ujian yang lebih tinggi dan tingkat kelulusan, mungkin tergoda untuk berpikir bahwa budaya sekolah terlalu samar untuk diprioritaskan.

Suatu budaya akan menjadi kuat atau lemah tergantung pada interaksi antara orang-orang dalam organisasi, katanya. Dalam budaya yang kuat, ada banyak interaksi yang tumpang tindih dan kohesif di antara semua anggota organisasi. Akibatnya, pengetahuan tentang karakter khas organisasi - dan apa yang diperlukan untuk berkembang di dalamnya - tersebar luas dan diperkuat. Dalam budaya yang lemah, interaksi yang jarang membuat orang sulit mempelajari budaya organisasi, sehingga karakternya hampir tidak terlihat dan komitmen terhadapnya jarang atau sporadis.

Keyakinan, nilai-nilai, dan tindakan akan menyebar terjauh dan diperkuat dengan kuat ketika semua orang berkomunikasi dengan orang lain. Dalam budaya sekolah yang kuat, para pemimpin berkomunikasi langsung dengan guru, staf, pengawas, supervisor, dan keluarga siswa, yang juga semuanya berkomunikasi langsung satu sama lain. Suatu budaya lebih lemah ketika komunikasi terbatas dan ada lebih sedikit koneksi. Misalnya, jika guru tertentu tidak pernah mendengar langsung dari kepala sekolah mereka, staf terus-menerus dikeluarkan dari komunikasi, atau kelompok anggota staf yang beroperasi terpisah dari yang lain, akan sulit bagi pesan tentang kepercayaan dan komitmen bersama untuk menyebar.

Selain budaya sekolah yang harus dibangun dengan baik di sekolah, variabel lain yang harus diperhatikan adalah etika profesi. Etika profesi pendidikan harus dipegang teguh oleh kepala sekolah, guru, dan staf. Jeder (2013) berdasarkan penelitiannya menyimpulkan pelatihan profesional di bidang pendidikan menyiratkan, di samping spesialisasi yang sangat baik dan pelatihan psiko-pedagogis, aspek lain yang sangat penting, dengan dampak langsung dan kuat pada seluruh proses pendidikan garis besar profil etika guru masa depan. Pekerjaan ini berfokus pada pendekatan berikut: (1) peran mempelajari etika pendidikan dalam pelatihan untuk karir mengajar; (2) aspek kritis mengenai praktik pengajaran dan evaluasi; (3) tanggung jawab etika guru dalam mendekati berbagai jenis kurikulum, yakni kurikulum tersembunyi (hidden curriculum), kurikulum nol (null curriculum), kurikulum hantu (phantom curriculum), kurikulum yang digunakan (curriculum in use), kurikulum retoris (rhetorical curriculum); dan (4) strategi refleksi tentang perilaku etis dalam pendidikan.

Etika kerja adalah bidang budaya yang mengikuti aturan dominan budaya dan masyarakat. Topik tersebut saat telah dipelajari lebih banyak dibandingkan dengan topik lain yang terkait dengan pekerjaan bidang pendidikan. Hasil penelitian Chanzanagh dan Nejat (2010) menunjukkan bahwa ada hubungan yang bermakna antara etika kerja dan nilai-nilai guru di bidang budaya, politik, dan ekonomi. Pendekatan teoritis penelitian tersebut didasarkan pada teori Weber dan mempelajari hubungan antara etika kerja dan nilai-nilai individu. Budaya kerja terkait dengan proses sosialisasi dalam keluarga dan sistem pendidikan masing-masing negara.

Sistem pendidikan sebagai landasan modern, untuk pembentukan landasan psikologis perkembangan sosial, harus secara sistematis memindahkan budaya ke pikiran generasi penerus. Perlu dicatat bahwa sistem pendidikan di setiap masyarakat memiliki tanggung jawab selain mentransfer nilai-nilai dan norma-norma umum masyarakat itu kepada generasi baru, juga memiliki tugas mewariskan etika dan nilai-nilai yang mendominasi dalam masyarakat. Sebenarnya, budaya sekolah disebut bidang budaya 
masyarakat yang mencakup kepercayaan dan nilai-nilai kerja yang mengikuti aturan umum yang dominan tentang budaya dan masyarakat.

Etika profesi pendidikan dengan demikian harus dijunjung tinggi oleh sekolah (Moeidfar, 2001). Masalah ini telah menjadi salah satu kompleksitas dalam mengakses pembangunan multilateral di negara (Rajabzade, 1997; Gunawan, dkk., 2008). Penelitian Sunar dan Tabancali (2012) menganalisis seberapa banyak kepala sekolah yang bekerja di sekolah dasar dan menengah berperilaku sesuai dengan prinsipprinsip etika dalam perilaku mereka sesuai dengan persepsi mereka sendiri dan guru mempertimbangkan variabel jenis kelamin, senioritas, usia dan tingkat pendidikan. Prinsip etika dipisahkan menjadi 6 dimensi. Dimensi-dimensi ini adalah toleransi, keadilan, tanggung jawab, kejujuran, demokrasi, dan rasa hormat.

Etika adalah tentang baik-buruk, persepsi salah-benar yang mewujudkan perilaku. Perilaku tidak bermoral, seperti berbohong, mencuri, menyuap, tidak melakukan tugas sesuai dengan peraturan dan alasan favoritisme dan pimpinan harus menjadi panutan bagi staf mereka dengan cara ini. Subyek etika dalam manajemen pendidikan adalah subjek sensitif yang mempengaruhi kelompok besar. Setiap administrator yang bekerja di bidang pendidikan diharapkan berperilaku sesuai dengan prinsip etika. Administrator harus mengutamakan kepentingan masyarakat dan harus melaksanakan tanggung jawab untuk masyarakat.

Subyek etika dalam manajemen sekolah adalah subyek yang selalu ditekankan dengan hati-hati (Gunawan, 2018). Mungkin tanggung jawab sosial paling penting dari sekolah dapat menjadi model dengan menggunakan kekuatannya sesuai dengan prinsip-prinsip etika. Karena itu, pengurus sekolah memikul tanggung jawab yang luar biasa. Administrator sekolah dapat berperilaku sesuai dengan aturan etika dan memberikan prinsip etika untuk dilembagakan di sekolah mereka sebagai institusi. Pertanyaan penelitian ini adalah apakah ada pengaruh yang signifikan variabel budaya sekolah terhadap etika profesi?

\section{METODE}

Penelitian ini merupakan bagian dari program penelitian tahun ketiga dengan judul: Pengembangan Model Pemberdayaan Sumber Daya Manusia Sekolah Menengah Pertama Berbasis Pesantren dengan Pendekatan Soft System Methodology, yang dilaksanakan pada tahun 2017, 2018, dan 2019. Program penelitian tersebut dilaksanakan di SMP Berbasis Pondok Pesantren di Jawa Timur Indonesia. Penelitian ini didanai oleh Kementerian Riset, Teknologi, dan Pendidikan Tinggi. Penelitian ini dilaksanakan dengan pendekatan kuantitatif. Variabel penelitian pada artikel ini adalah budaya sekolah sebagai variabel prediktor dan etika profesi sebagai variabel kriterium. Hipotesis yang diuji adalah: ada pengaruh yang signifikan budaya sekolah terhadap etika profesi.

Penelitian ini merupakan bagian dari proses pengukuran variabel yang menjadi faktor keberhasilan penerapan model pemberdayaan sumber daya manusia sekolah menengah pertama berbasis pesantren dengan pendekatan soft system methodology. Penelitian dilaksanakan di SMP An Nur Malang. Responden atau sampel penelitian adalah: (1) 1 orang kepala sekolah; (2) 20 orang guru; dan (3) 10 orang tenaga administrasi sekolah (TAS). Instrumen yang digunakan untuk mengukur variabel penelitian adalah angket. Analisis data menggunakan: analisis deskriptif dan regresi sederhana. Analisis deskriptif menghitung: rerata, deviasi standar, skor maksimum; skor minimum; range; dan interval. Sedangkan analisis regresi sederhana selain untuk menguji hipotesis, digunakan untuk mengetahui kontribusi dari variabel prediktor terhadap variabel kriterium.

\section{HASIL}

\section{Deskripsi Data}

Berdasarkan hasil deskripsi data variabel budaya sekolah (X) diketahui: rerata 116; deviasi standar 8,27; skor maksimum 129; skor minimum 97; range 32; dan interval 8. Adapun deskripsi frekuensi variabel budaya sekolah (X) disajikan pada Tabel 1. 
Tabel 1 Distribusi Frekuensi Variabel Budaya Sekolah (X)

\begin{tabular}{cccc}
\hline Kategori & Interval & f & \% \\
\hline Sangat rendah & $64-70$ & 2 & 6,45 \\
Rendah & $71-77$ & 14 & 45,16 \\
Cukup & $78-84$ & 8 & 25,81 \\
Tinggi & $85-91$ & 6 & 19,35 \\
Sangat tinggi & $92-98$ & 1 & 3,23 \\
\hline & Total & $\mathbf{3 1}$ & $\mathbf{1 0 0}$ \\
\hline
\end{tabular}

Berdasarkan hasil deskripsi data variabel etika profesi (Y) diketahui: rerata 78,84; deviasi standar 6,62; skor maksimum 93; skor minimum 64; range 29; dan interval 7. Adapun deskripsi frekuensi variabel etika profesi (Y) disajikan pada Tabel 2.

Tabe 2 Distribusi Frekuensi Variabel Etika Profesi (Y)

\begin{tabular}{cccc}
\hline Kategori & Interval & f & \% \\
\hline Sangat rendah & $64-70$ & 2 & 6,45 \\
Rendah & $71-77$ & 14 & 45,16 \\
Cukup & $78-84$ & 8 & 25,81 \\
Tinggi & $85-91$ & 6 & 19,35 \\
Sangat tinggi & $92-98$ & 1 & 3,23 \\
\hline & Total & $\mathbf{3 1}$ & $\mathbf{1 0 0}$ \\
\hline
\end{tabular}

\section{Uji Hipotesis}

Analisis data dilakukan untuk menguji hipotesis penelitian. Berdasarkan hasil analisi regresi sederhana variabel budaya sekolah $(\mathrm{X})$ terhadap etika profesi $(\mathrm{Y})$ diketahui: koefisien regresi sebesar 0,537; dan signifikansi t sebesar 0,002 (Tabel 3). Jika mengacu pada nilai signifikansi t sebesar 0,002; maka signifikansi tersebut $<0,050$; sehingga hipotesis yang menyatakan ada pengaruh yang signifikan budaya sekolah terhadap etika profesi, diterima. Sehingga hasil penelitian ini menyimpulkan ada ada pengaruh yang signifikan budaya sekolah terhadap etika profesi.

Tabel 3 Analisis Regresi Sederhana Budaya Sekolah (X) terhadap Etika Profesi (Y)

\begin{tabular}{ccccccc}
\hline $\mathbf{R}$ & $\mathbf{R}$ Square & Sum of Squares & $\mathbf{d f}$ & $\begin{array}{c}\text { Mean } \\
\text { Squares }\end{array}$ & $\mathbf{t}$ & sig. \\
.537 & .289 & 936.228 & 1 & 32.284 & 3.431 & .002 \\
& & 30 & & & \\
\hline
\end{tabular}

Selanjutnya dicari indeks determinasi variabel prediktor terhadap variabel kriterium dengan berpedoman pada Tabel 3. Berdasarkan Tabel 3 diketahui $\mathrm{r}_{\text {square }}=0,289$; sehingga indeks determinasi variabel budaya sekolah (X) terhadap etika profesi (Y) sebesar: 28,9\%; dari hasil perhitungan $r_{\text {square }} \times 100=0,289 \times 100=28,9$. Dari perhitungan tersebut dapat diketahui variabel etika profesi (Y) 71,1\% dipengaruhi oleh variabel lain selain variabel budaya sekolah (X).

Selanjutnya dicari persamaan regresi variabel prediktor terhadap variabel kriterium dengan berpedoman pada Tabel 4. Berdasarkan Tabel 4, persamaan regresi yang terbentuk adalah: $\hat{\mathrm{Y}}=28,923$ + 0,43X. Berdasarkan persamaan regresi tersebut dapat dijelaskan: (1) konstanta 28,923 menyatakan 
bahwa jika tidak ada kenaikan skor pada variabel budaya sekolah (X), maka skor variabel etika profesi (Y) sebesar 28,923; dan (2) koefisien regresi 0,43 pada variabel budaya sekolah (X) menyatakan bahwa setiap penambahan satu skor variabel budaya sekolah (X) akan memberikan kenaikan pada variabel etika profesi (Y) sebesar 0,43.

Tabel 4 Coefficients ${ }^{\mathrm{a}}$

\begin{tabular}{lcccccc}
\hline Model & \multicolumn{2}{c}{$\begin{array}{c}\text { Unstandardized } \\
\text { Coefficients } \\
\text { Std. Error }\end{array}$} & $\begin{array}{c}\text { Standardized } \\
\text { Coefficients } \\
\text { Beta }\end{array}$ & t & sig. \\
\hline \multirow{2}{*}{1} & $\begin{array}{c}\text { (Constant) } \\
\text { B }\end{array}$ & 28.923 & 14.586 & & 1.983 & .057 \\
& $\mathrm{X}$ & .430 & .125 & .537 & 3.431 & .002 \\
\hline
\end{tabular}

a. Dependent Variable: $Y$

\section{PEMBAHASAN}

Hasil penelitian ini menyimpulkan ada pengaruh yang signifikan budaya sekolah terhadap etika profesi. Indikator budaya sekolah yang diukur adalah: (1) pedoman perilaku warga sekolah; (2) proses mewariskan budaya sekolah kepada anggota baru; (3) acuan menyelesaikan masalah sekolah; (4) tanggung jawab terhadap tugas yang diemban dalam organisasi; (5) inovasi dan pengambilan risiko dalam mencapai tujuan sekolah; (6) tujuan sekolah sebagai arah dalam melaksanakan tugas; (7) kerja sama dalam melaksanakan tugas; (8) motivasi dan komunikasi yang baik oleh pimpinan sekolah; (9) pengawasan sekolah; (10) perasaan bangga terhadap sekolah; (11) sistem kompensasi; (12) sarana kritik dan pemberian masukan kepada sekolah; dan (13) pola komunikasi di sekolah.

Penelitian ini selaras dengan hasil penelitian Uğurlu (2009) yang menyimpulkan ketika karakteristik budaya diterapkan pada sekolah, diamati bahwa perilaku pemimpin sekolah telah menentukan efek pada struktur budaya sekolah. Otonomi pribadi, struktur, dukungan, identitas, kinerja-penghargaan, toleransi konflik, dan karakteristik toleransi risiko dalam penelitian tersebut dibahas sebagai karakteristik budaya sekolah dalam memahami struktur budaya sekolah, dan proses pengembangan sekolah dan sudut pandang instruktur tentang hubungan tingkat antara karakteristik dan budaya sekolah dievaluasi.

Salah satu kemungkinan bagaimana beradaptasi secara fleksibel terhadap perubahan dalam masyarakat yang sedang berkembang, yang sangat mempengaruhi lingkungan sekolah, adalah menerapkan pendekatan pemasaran yang terdiri dari sistem kompleks faktor-faktor yang saling terkait yang berfokus pada sekolah dan lingkungan sekolah - semua dengan tujuan untuk membuat gambar positif. Penelitian Šramová (2013) menyajikan temuan terkait dengan persepsi budaya sekolah oleh murid, guru, karyawan dan orang tua. Faktor-faktor kunci, yang membentuk sikap terhadap sekolah, mencakup kepuasan siswa, karyawan dan orang tua, komunikasi timbal balik, proses evaluasi yang menegaskan upaya pencegahan risiko yang efektif dan menumbuhkan iklim sekolah yang positif.

Studi Freire dan Branco (2019) mengklaim bahwa dinamika antara diri dan budaya yang mengarah pada pengembangan ontogenetik ditimbulkan oleh interaksi sosial semiotik-afektif; dan bahwa kualitas interaksi semacam itu adalah produk dari sejarah panjang mediasi sosial dari proses makna-diri. Mempertimbangkan pengembangan diri sebagai aspek fundamental dari pendidikan, penelitian tersebut dibangun berdasarkan pendekatan konstruktivisme semiotik-kultural dan teori diri dialogis (dialogical self-theory) untuk memahami hubungan antara budaya-diri-lain (self-other-culture). Analisis lintasan pendidikan menunjukkan bagaimana hubungan dialogis mendukung perubahan yang dialami oleh guru sebagai pembelajar.

Hasil dari penelitian Freire dan Branco (2019) menyarankan perubahan yang signifikan dari kualifikasi diri awal yang mengganggu sebagai siswa menjadi munculnya suara percaya diri tentang dirinya sebagai pembelajar yang cerdas dan cakap. Analisis menyarankan praktik pengajaran memiliki potensi untuk memobilisasi makna negosiasi dan partisipasi aktif, menghasilkan kemungkinan integrasi sistem pengetahuan, dan pengembangan diri yang berorientasi pada masa depan. Budaya sekolah dikenal penting untuk hasil siswa yang positif. 
Studi Kumar (2019) meneliti situasi unik di mana dua budaya belajar yang berbeda - yang disebarkan oleh guru negeri dan swasta - hidup berdampingan di lingkungan belajar yang sama di Delhi, India. Berdasarkan data dari empat sekolah negeri, ruang kelas guru-guru yang diamati cenderung menunjukkan diskriminasi terhadap orang yang tidak belajar, fokus pada disiplin dan hafalan, dan penggunaan waktu yang tidak efisien. Ruang kelas guru swasta yang diamati menampilkan gaya pengajaran yang inklusif dan kreatif serta penggunaan waktu yang lebih efisien. Guru negeri tidak diamati untuk mengadopsi perilaku spesifik seperti guru swasta, sementara guru swasta tampaknya dibatasi oleh lingkungan sekolah pemerintah.

Etika adalah seperangkat standar atau kode yang memasukkan definisi kegiatan manusia sesuai dengan hak asasi manusia dan kesalahan serta baik dan buruk (Owens, 1978; Andriningrum dan Gunawan, 2018). Menurut Carroll (1989), etika didefinisikan sebagai harmoni antara tindakan, keputusan, dan perilaku dan norma dan standar yang berlaku di masyarakat. Menurut definisinya, etika adalah tentang keputusan dan perilaku individu, namun norma dan standar yang berlaku di masyarakat memiliki peran penting dalam pembentukan perilaku ini.

Indikator etika profesi yang diukur dalam penelitian ini adalah: (1) tanggung jawab profesi; (2) kepentingan publik; (3) integritas; (4) obyektivitas; (5) kompetensi dan kehati-hatian profesional; (6) kerahasiaan; (7) perilaku profesional; dan (8) standar teknis. Sekolah adalah tempat di mana orang tinggal dan bekerja. Seperti organisasi sosial lainnya, sekolah menggunakan kekuatan, struktur, logika dan nilai dan memiliki kekuatan pada orang untuk menjawab pertanyaan mereka dan memenuhi kebutuhan mereka (Owens, 2000; Gunawan dan Benty, 2017; Sobri, dkk., 2018). Oleh sebab itu, pemberdayaan sumber daya manusia yang dimiliki sekolah mutlak harus dilaksanakan secara optimal (Kusumaningrum, dkk., 2018a; Kusumaningrum, dkk., 2018b).

Tidak cukup bagi manajer sekolah untuk berperilaku sesuai dengan prinsip-prinsip yang tercantum untuk menciptakan sekolah yang etis. Budaya sekolah yang etis harus diciptakan untuk memastikan bahwa semua orang di sekolah mematuhi prinsip-prinsip etika. Langkah pertama untuk itu adalah menyiapkan program aturan etika untuk sekolah. Program ini dapat dilihat sebagai hukum etika sekolah (Cherrington, 1980; Furnham, 1987; Sultoni, dkk., 2018c; Nurabadi, dkk., 2018). Tidak ada tempat untuk kediktatoran di sekolah. Jika manajer sekolah mengharapkan guru berperilaku sesuai dengan nilai-nilai etis, maka ia harus melakukannya terlebih dahulu (Gunawan, 2018; Pertiwi, dkk., 2018; Sultoni, dkk., 2018a; Bafadal, dkk., 2018a; Bafadal, dkk., 2018b).

Manajeryang mencoba menyelesaikan prinsip-prinsip etika dengan budaya sekolah, menyuarakannya dalam volume tinggi. Langkah lain untuk menciptakan budaya sekolah yang etis adalah melatih pekerja tentang etika, memberikan seminar yang diperlukan dalam layanan. Adalah penting dan penting bagi setiap orang untuk memiliki informasi tentang perilaku yang etis atau tidak etis (Gunawan, 2015; Sultoni, dkk., 2018b; Sudharta, dkk., 2017; Harmini, dkk., 2017; Agustina, dkk., 2018) dan harus dibuat jelas apa yang harus dilakukan ketika menghadapi perilaku yang tidak etis. Ini akan menjadi langkah penting untuk mengembangkan visi yang sesuai dengan filosofi pendidikan dan membuat semua pemangku kepentingan percaya dengan tulus.

\section{SIMPULAN}

Penelitian ini menyimpulkan ada pengaruh yang signifikan variabel budaya sekolah $(\mathrm{X})$ terhadap etika profesi $(\mathrm{Y})$. Hasil penelitian ini mengisyaraktkan perlunya sekolah mengembangkan budaya sekolah yang baik dalam rangka mengembangkan penyelenggaraan pendidikan sekolah menjadi lebih baik, dengan memegang teguh etika profesi. Budaya sekolah yang di dalamnya terdapat nilai dan norma budaya akan menjadi patokan dalam menyusun etika profesi. Dan etika profesi itu nantinya menjadi acuan dalam menjalankan tugas keprofesian guru. 


\section{DAFTAR RUJUKAN}

Agustina, N. E., Sumarsono, R. B., dan Gunawan, I. (2018). Implementation of School and Community Relationship Techniques (A Case Study in SDN Karangbesuki 2 Malang, Indonesia). Proceeding 1st International Conference on Early Childhood and Primary Education (ECPE 2018), Published by Atlantis Press, 244, 145147.

Andriningrum, H., dan Gunawan, I. (2018). Cultivatation of Healthy Life for Students in School: A Literature Review. Proceedings of the International Conference on Education and Technology (ICET 2018), Published by Atlantis Press, 285, 223-224.

Bafadal, I., Juharyanto, Nurabadi, A., dan Gunawan, I. (2018a). Principal Leadership and its Relationship with Student Learning Achievements: A Regression Analysis. Proceeding 3rd International Conference on Education Management and Administration (CoEMA 2018), Published by Atlantis Press, 269, 156-158.

Bafadal, I., Juharyanto, Nurabadi, A., dan Gunawan, I. (2018b). The Influence of Instructional Leadership, Change Leadership, and Spiritual Leadership Applied at Schools to Teachers' Performance Quality. Proceedings of the International Conference on Education and Technology (ICET 2018), Published by Atlantis Press, 285, 197-200.

Carroll, A. B. (1989). Business \& Society-Ethics \& Stakeholder Management. New York: South-Western Publishing Co.

Cherrington, D. J. (1980). The Work Ethic: Working Values and Values that Work. New York: AMACOM.

Chanzanagh, H. E., dan Nejat, J. (2010). Values and Work Ethic in Iran: A Case Study on Iranian Teachers. Procedia - Social and Behavioral Sciences, 5, 1521-1526.

Freire, S. F. C. D., dan Branco, A. U. (2019). Dynamics between Self and Culture in School: A Dialogical and Developmental Perspective. Learning, Culture and Social Interaction, 20, 24-31.

Furnham, A. (1987). Predicting Protestant Working Beliefs. European Journal of Personality, 1, 93-106.

Gunawan, I. (2015). Values and Ethics in Educational Leadership: An Idea of Character Building of Students. Conference Proceedings Character Education in Indonesia Concepts and Applications in Primary Schools, PGSD IKIP PGRI MADIUN, 9 Juni, 1-13.

Gunawan, I. (2017). The Implementation of Lesson Study Based Learning Management and the Effect toward Students' Activeness in Lecturing. Jurnal Pendidikan dan Pembelajaran, 24(2), 51-63.

Gunawan, I. (2018). Kepemimpinan Pendidikan: Suatu Pengantar. Universitas Negeri Malang, UM Press.

Gunawan, I., dan Benty, D. D. N. (2017). Manajemen Pendidikan: Suatu Pengantar Praktik. Bandung: Alfabeta.

Gunawan, I., Wardani, A. D., dan Thohari, A. (2008). Hubungan Penerapan Metode Pembelajaran Kooperatif Model TGT (Teams, Game, and Tournament) Guru Mata Pelajaran Fisika dengan Tingkat Pemahaman dan Motivasi Belajar Siswa SMA Negeri Se-Kota Malang. Laporan penelitian tidak diterbitkan. Malang: Universitas Negeri Malang, Dirjen Dikti Kemdiknas.

Hardika, Aisyah, E. N., Gunawan, I. (2018). Facilitative Learning to Improve Student Learning Creativity. Proceeding 3rd International Conference on Education Management and Administration (CoEMA 2018), Published by Atlantis Press, 269, 186-189.

Harmini, S., Kartini, H., dan Gunawan, I. (2017). Filsafat dan Teori Pendidikan. Malang: Penerbit Universitas Negeri Malang, Penerbit UM Press.

Jeder, D. (2013). Teachers' Ethic Responsibilities in the Practice of Education and Training. Procedia - Social and Behavioral Sciences, 92, 432-436.

Kumar, A. (2019). Cultures of Learning in Developing Education Systems: Government and NGO Classrooms in India. International Journal of Educational Research, 95, 76-89.

Kusumaningrum, D. E., Sumarsono, R. B., dan Gunawan, I. (2018a). Empowering the Principal of Boarding House-Based Junior High School in East Java Province Indonesia. Proceeding 3rd International Conference on Education Management and Administration (CoEMA 2018), Published by Atlantis Press, 269, 147-151.

Kusumaningrum, D. E., Sumarsono, R. B., dan Gunawan, I. (2018b). Teachers Empowerment of Pesantren-Based Junior High School East Java Province Indonesia. Journal of Social Sciences and Humanity Studies, 4(3), 29-33.

Moeidfar, S. (2001). The Work Ethic and Effects of personal and Social Factors. Tehran: Nashre Moasseseye Kar Va Tamine Ejtemaiy.

Mursidik, E. M., Tryanasari, D., dan Gunawan, I. (2013). Pengembangan Buku Pedoman Microteaching Berbasis Lesson Study Prodi PGSD FIP IKIP PGRI MADIUN. Jurnal Pendidikan, 19(1), 1-26. 
Nurabadi, A., Sucipto, Juharyanto, dan Gunawan, I. (2018). The Implementation of Education Management Standards in the School Laboratory State University of Malang for Improving Educational Quality. Proceeding 3rd International Conference on Education Management and Administration (CoEMA 2018), Published by Atlantis Press, 269, 127-132.

Owens, J. (1978). Ethical Theory and Business Decisions. Maryland: The American University, Management Education LTD.

Owens, R. G. (2000). Organizational Behavior in Education: Instructional Leadership and School Reform. New York: Allyn \& Bacon.

Pertiwi, A. K., Cahyani, S. S. A., Diana, R. C., dan Gunawan, I. (2018). Analisis Interaksi Simbolik Kyai dan Santri dalam Perspektif Kepemimpinan Berbasis Nilai dan Etika. JMSP: Jurnal Manajemen dan Supervisi Pendidikan, 2(3), 185-191.

Rajabzade, A. (1997). Values and Weakness of Work Ethic in Iran. Journal of Namee Pajouhesh, 5, 60-78.

Schein, E. H. (2014). Organizational Culture and Leadership. San Francisco: John Wiley \& Sons, Inc.

Sobri, A. Y., Bafadal, I., Nurabadi, A., dan Gunawan, I. (2018). Development of Mentoring Modules Based on Self-Reflection for Beginner Principal. Proceeding 3rd International Conference on Education Management and Administration (CoEMA 2018), Published by Atlantis Press, 269, 133-139.

Šramová, B. (2013). School Culture as Part of Marketing Orientated Approach. Procedia - Social and Behavioral Sciences, 106, 2316-2322.

Sudharta, V. A., Mujiati, M., Rosidah, A., dan Gunawan, I. (2017). Gaya Kepemimpinan Kepala Sekolah dalam Perspektif Psikologi. Jurnal Manajemen dan Supervisi Pendidikan, 2(2), 109-123.

Sultoni, Gunawan, I., dan Rosalinda, T. N. (2018a). Pengaruh Pembentukan Tim dan Kepemimpinan Spiritual terhadap Motivasi Diri Mahasiswa. JMSP: Jurnal Manajemen dan Supervisi Pendidikan, 2(3), 210-216.

Sultoni, Gunawan, I., dan Sari, D. N. (2018b). Pengaruh Etika Profesional terhadap Pembentukan Karakter Mahasiswa. JAMP: Jurnal Adminitrasi dan Manajemen Pendidikan, 1(3), 279-283.

Sultoni, Gunawan, I., dan Sari, D. N. (2018c). The Internalization of Character Values to Students: A Descriptive Study. Proceedings of the International Conference on Education and Technology (ICET 2018), Published by Atlantis Press, 285, 169-171.

Suminah, Gunawan, I., dan Murdiyah, S. (2018). Peningkatan Hasil Belajar dan Motivasi Belajar Siswa melalui Pendekatan Behavior Modification. Ilmu Pendidikan: Jurnal Kajian Teori dan Praktik Kependidikan, 3(2), 221-230.

Sunar, O. B., dan Tabancali, E. (2012). Ethic Behaviours of Schools Administrations. Procedia - Social and Behavioral Sciences, 46, 2457-2461.

Suraya, S. N., Hartini, dan Gunawan, I. (2012). Persepsi Mahasiswa Terhadap Kualitas Pelayanan Pendidikan FIP IKIP PGRI MADIUN. Jurnal Pendidikan, 18(1), 37-66.

Uğurlu, C. T. (2009). The Significance of School Culture in Elementary Schools in Terms of Organizational Development. Procedia - Social and Behavioral Sciences, 1(1), 1003-1007. 